\title{
Management of victims of stalking
}

\author{
Michele Pathé, Paul E. Mullen \& Rosemary Purcell
}

This article follows on from Mullen et al's (2001) earlier article in APT on the mangement of stalkers.

Victims of stalking are a diverse group, but most individuals who are subjected to the persistent pursuit of a stalker, regardless of age, gender or socioeconomic background, experience fear. Some suffer profound distress and lifestyle disruptions, and many experience a decline in their psychological and physical well-being. Stalking is not uncommon in today's society and there is evidence to suggest its incidence is increasing (Budd \& Mattinson, 2000). It is therefore anticipated that the victims of these behaviours will be presenting to law enforcement and health professionals in ever-expanding numbers. The efficacy of the interventions they receive will determine whether they can reclaim their lives and premorbid functioning or whether, through ignorance, they are condemned to continuing torment and chronic disability, to the detriment of society as a whole.

In this paper, we will provide an overview of the range of interventions aimed at assuaging the suffering of stalking victims. Obviously, the most useful approach to the management of these individuals is likely to be the timely disposition of their stalkers and resolution of the harassment, but it will not be a sufficient or achievable strategy in all cases. Indeed, without appropriate intervention, morbidity among stalking victims can persist long after the stalking has abated. We will also discuss the phenomenon of false claims of victimisation and their management.

\section{Victim types}

Like stalkers, stalking victims are not a homogeneous group. It is useful to categorise them according to their relationship with their stalker and the context in which the stalking activities arose. These groups, which are not mutually exclusive, are briefly summarised below. Further details can be found in Mullen et al (2000).

\section{Ex-intimates}

In this group, the victim is typically a female pursued by a former boyfriend or spouse, although the victim may be a male stalked by a girlfriend or wife and in some cases the victim and his or her stalker will share the same gender (Pathé et al, 2000). These victims are subjected to the widest range of harassment for often protracted periods, and they are more likely than those in other categories to be threatened and physically assaulted (Mullen et al, 1999). They commonly harbour excessive guilt for their poor choice of partners, a sentiment that may unfortunately be reinforced by loved ones and helping professionals.

\section{Casual acquaintances and friends}

This is probably the most common category for male victims - the stalking generally arises following a

Michele Pathé is Consultant Forensic Psychiatrist and Assistant Clinical Director at the Victorian Institute of Forensic Mental Health in Melbourne, Victoria. She is an honorary senior lecturer at Monash University in Melbourne and a Fellow in the Department of Criminology at the University of Melbourne. Her research interests include sex offender management, stalkers and stalking victims. Paul E. Mullen is Professor of Forensic Psychiatry at Monash University, Australia, and Director of Forensic Mental Health Services for the State of Victoria. His research interests in addition to stalking are in the relationship between mental disorder and offending behaviour and the long-term effects of child abuse. Rosemary Purcell is a PhD candidate at the Faculty of Medicine, Monash University. Her doctoral thesis is examining the incidence, nature and impact of stalking in a community sample. She is also a psychologist at the Victorian Institute of Forensic Mental Health where she is overseeing implementation and evaluation of support group services for victims of stalking. All three co-authored Stalkers and their Victims (Cambridge University Press, 2000), winner of this year's Manfred S. Guttmacher award from the American Psychiatric Association. 
casual social encounter. These victims are pursued for relatively briefer periods by stalkers with socially incompetent and intimacy-seeking motives, and they are much less likely to be exposed to violence (Mullen et al, 1999).

\section{Professional contacts}

All whose profession brings them into regular contact with people who are lonely or have a mental disorder are vulnerable to being stalked. Teachers, health care providers and lawyers appear to be at particular risk, attracting intimacy-seekers and socially incompetent, resentful and even predatory stalkers. Occasionally, the termination of a long-term therapeutic relationship can give rise to rejected stalking patterns.

\section{Work contacts}

Victims of stalking within the work environment are characteristically pursued by a socially incompetent fellow worker, employer or employee, or a resentful colleague, customer or employee. The latter usually arises in the context of major organisational change or disciplinary action against the perpetrator, such that he or she comes to believe he or she has been passed over in favour of the victim. Such cases have occasionally erupted in extreme violence that is not confined to the primary victim.

\section{Strangers}

Stalkers from motivational categories other than the rejected can victimise strangers (although some, such as the intimacy-seekers, can become violent in the context of perceived rejection). While victims of predatory stalkers can be at significant risk of violence (usually sexual), most victims pursued by strangers are, on the available evidence, in less danger of being attacked than those who know their stalker, especially intimately (Mullen et al, 1999). However, for those targeted by strangers, confusion and alarm is common. One of our patients received a series of packages in the mail from an anonymous person. The initial offerings were relatively benign (a bouquet of flowers, then a tin of confectionery), but became more bizarre (fake tattoos, a bomber jacket) and offensive (human faeces, used condoms). The worst aspect for this woman was her inability to make sense of the harassment and the perpetrator's reason for targeting her. She became fearful of venturing out because she had no idea of her stalker's identity.

\section{The famous}

These include stars of television, radio and film, sports champions, writers, royalty, politicians and other public figures. They attract intimacy-seekers, social incompetents, the resentful and the predatory. Such is the extent of the problem that a whole industry has developed around protecting the famous, many of whom must contend with more than one stalker at any given time.

\section{False victims of stalking}

A small proportion of those claiming to be victims of stalking prove to be false victims, either as a consequence of conscious fabrications or serious psychopathology (Mohandie et al, 1998; Pathé et al, 1999) (see Box 1). On occasion, stalkers accuse their victim of stalking them, often in retaliation but also to maintain contact with the victim through the legal system. Former genuine victims may falsely allege that they are again being stalked, ascribing malevolent intent to innocent situations. This arises in the context of the hypervigilance and distrust that is the legacy of genuine stalking victims, and through increasing social isolation - limited opportunities for reality testing.

Delusions that one is being watched and followed, typically by entire networks of people, can be encountered as part of a delusional system, usually of the persecutory or erotomanic type. These individuals tend to present in later life and to live an isolated existence, some having never married. Partition delusions, or the belief that people, electricity or some other force can pass through structures that would ordinarily pose a barrier to such passage (Howard et al, 1992), are not uncommon. One elderly woman believed that laser lights were being beamed through her bedroom wall at night by an unknown male who intended to rape her. These are tortured individuals, many of whom contemplate suicide or adopt extreme measures to protect themselves against their perceived persecutors.

In factitious disorders, individuals consciously simulate physical or psychological symptoms because of an intrapsychic need to assume the sick role (Janofsky, 1994). Similarly, factitious victims adopt the victim role to gratify their dependency needs. The remaining group are malingerers, who feign or exaggerate victim status purely for external incentives such as financial rewards. This group is uncommon in our experience, perhaps a reflection of the limited financial incentives for crime victims in our jurisdiction. 
Box 1 False claims of victimisation

Stalkers who claim to be victims

Delusions of being stalked

The previously stalked

The factitious disorder

The malingerer

\section{The impact of stalking}

Victim studies consistently demonstrate the adverse impact of being stalked. There are several factors that contribute to the high levels of morbidity observed in stalking victims. First, stalking is not a single, circumscribed offence but a crime characterised by repetition, persistence and unpredictability. The behaviours evoke fear, hypervigilance and distrust, which have a destructive impact upon the victim's interpersonal relationships and support network. Feelings of abandonment and a loss of control over their situation are common themes among stalking victims. These may be reinforced by ineffectual or unsympathetic responses from the criminal justice system and helping agencies, usually born out of the ignorance that continues to surround stalking, even in professional circles.

Studies of stalking victims (Jason et al, 1984; Pathé \& Mullen, 1997; Hall, 1998; Budd \& Mattinson, 2000) have found that most are forced to adjust their daily routine in response to being stalked and for many there are major lifestyle disruptions. These include withdrawal from social activities, abandoning work or school, increasing security and altering one's physical appearance. One woman known to us withdrew from gym classes, obtained an unlisted phone number, resigned from her job, moved to a neighbouring suburb, changed her motor vehicle, radically altered her hairstyle and gained weight in a bid to escape her former boyfriend's harassment, to no avail. She ultimately moved to another state and the stalking has apparently stopped, at enormous personal and financial cost.

Victim studies and clinical experience have also shown that many stalking victims experience a deterioration in mental and/or physical well-being. The most common psychiatric diagnoses are posttraumatic stress disorder (PTSD), other anxiety disorders and depression. In a survey of 100 self-selected stalking victims (Pathé \& Mullen, 1997), over 80\% reported increased anxiety and arousal in response to the stalking. A third met the full DSM-IV criteria for PTSD (American Psychiatric Association, 1994) with intrusive recollections of the stalking, symptoms of excessive arousal, often manifest in sleep disturbances, and hypervigilance, avoidance behaviours and feelings of estrangement from others. A quarter of the sample admitted they had considered or attempted suicide, regarding this as their only escape from a perceived life sentence of stalking. A quarter of the sample increased their cigarette and alcohol consumption in response to the stalking, and some said they had misused other prescription drugs to self-medicate intolerable symptoms of stress. Many of these victims experienced physical symptoms such as nausea and fatigue, and exacerbations of pre-existing medical conditions like asthma, hypertension and psoriasis.

Systematic assessment of stalking victim populations using standardised measures of psychological distress have lent further weight to these earlier studies. Westrup et al (1999) compared 36 stalking victims to 43 who had experienced less severe and frequent harassment ('harassed' group) and 48 controls, all subjects being female college students. Psychological impact was measured using the PTSD Scale (Foa, 1995), the Symptom Check List-90-R (SCL90-R; Derogatis, 1977) and the Self-Report Interpersonal Trust Scale (MacDonald et al, 1972). Stalking victims had significantly higher scores on a number of subscales of the SCL-90, in particular depression, and they exhibited heightened interpersonal sensitivity. The PTSD Scale revealed significantly more post-traumatic symptoms and of greater severity relative to comparison groups.

Third parties may also be affected. The primary victim's family members, partner, children, friends, work colleagues and neighbours may be threatened and even assaulted, especially if they are perceived to be impeding access to the object of attention (Mullen \& Pathé, 1994). As for primary victims, however, threats and violence are not a prerequisite for the development of distress and dysfunction. The elderly mother of a stalking victim under our care was subjected to repeated 'hang up' phone calls in the early hours and obscene messages scrawled in chalk on her driveway, such that her health deteriorated and she was forced to forfeit her independence and move to a retirement home. Her daughter maintains that it is all her fault for bringing the stalker (her ex-husband) into her mother's life.

\section{How to combat stalking}

Individuals who are being actively stalked may seek the advice of health professionals. In the first 
instance, the treating professional must ensure that there are strategies in place to protect the victim and others who might be at risk. It is essential that the victim and involved parties be apprised of strategies that discourage the stalker's intrusions. Where the stalker is known to be in treatment or under the supervision of a probation or parole officer, the victim's therapist should ensure that those charged with the stalker's care are alerted to any continuing transgressions. The following is a useful guide for stalking victims (see Box 2 for a summary).

\section{Avoid contact and confrontation}

Victims should at the earliest juncture give a firm, unequivocal message to the stalker that their attention is unwanted, and that they do not want a relationship in those cases where the establishment or restoration of a relationship is the stalker's apparent goal. Thereafter, they should resist all contact with him or her, since pleading and negotiating is unlikely to dissuade the stalker. Their stalker is either unwilling or unable, by virtue of mental illness, to respect the victim's wishes and further contact will only reward and acknowledge his or her efforts.

\section{Inform others}

Victims, through shame, embarrassment or a failure to appreciate the potential seriousness of their situation, may try to 'go it alone'. They should be encouraged to notify the police and to advise family, friends and work colleagues and neighbours where appropriate. Informing significant others helps galvanise support and protection for the victim, prevents the unwitting disclosure of information to the stalker and enables others who may also be at risk to take necessary precautions.

\section{Documentation}

Victims should document suspicious incidents and retain any evidence of stalking. Letters and other unsolicited material must be kept, not returned to sender, phone calls should be recorded on answering
Box 2 Strategies to combat stalking

Avoid contact and confrontation

Inform others

Document and retain evidence

Restraining orders (not a universal strategy)

Appropriate security measures

machine cassettes and police incident reports and other important documents (with copies) should be securely filed.

\section{Restraining orders}

These are protective injunctions, known in other jurisdictions as intervention orders, apprehended violence orders, or non-molestation orders. These should not be regarded as an automatic first-line approach to stalkers, as they are by no means universally effective. Indeed, Tjaden \& Thoennes (1998) reported that $81 \%$ of male and $69 \%$ of female victims who obtained a restraining order claimed that it was violated by their stalker. These orders are a civil remedy and as such they pit the victim against the stalker and they can only be enforced once they have been breached. ${ }^{1}$ They have no provision for mandatory assessment and, if required, mandated treatment for the offender - the intervention that may most effectively bring an end to the stalking.

Restraining orders tend to be less effective in certain types of stalker. For ex-intimates, particularly those narcissistic individuals who have a deep emotional investment in the relationship, the personal humiliation of being rejected can be exacerbated by the perceived public humiliation of a restraining order, with occasional violent consequences. In the case of deluded stalkers, in particular the erotomanic, such orders are irrelevant or are regarded as a further test of their love and devotion. A woman with erotomania stalked her employer for months, convinced he was secretly married to her despite his wife and children and a restraining order against her. After repeated breaches

1. In the UK, however, under the Protection from Harassment Act (1997), there are provisions for the linking of restraining orders and civil damages to the criminal offences of 'harassment' and 'putting people in fear of violence'. Courts can impose restraining orders as a condition of sentencing. Any subsequent prohibited contact with the victim constitutes a breach of the order, potentially punishable by a prison sentence with a substantial maximum penalty. This system may provide an incentive for some stalkers to discontinue their harassment and enable early intervention in those cases where the stalker fails to desist. Court-imposed restraining orders overcome the difficulties often encountered with the victim-initiated system, such as lengthy and potentially dangerous delays between the application and hearing and the expense to the victim of petitioning the court and obtaining legal representation. Furthermore, they may deflect some of the wrath and resentment that victims often incur from their stalker. 
of the order, a magistrate sentenced her to a prison term, but the woman was unfazed. She believed that her imagined 'husband' had orchestrated her incarceration to 'protect' her from the repeated intrusions of the police!

Stalking victims should be aware that not only can protective injunctions fail to resolve the harassment but they may in some cases exacerbate the problem. Victims would be well advised to consult a forensic expert before contemplating this course of action. It must be emphasised that stalking victims intending to apply for an order should do so as early as possible in the course of the stalking, and that the period immediately following the issuance of the order may be one of heightened risk of violence. Restraining orders do not bring with them any guarantees of safety nor of resolution of harassment.

\section{Cyberstalking}

Stalking via e-mail or the internet is most dangerous when it extends off-line. Individuals should remove themselves from any on-line situation that becomes hostile by logging off. They should not respond to provocation on-line ('flaming'), nor flirt or give out personal details. Those who harass in cyberspace must be told that their communications are unwanted. The victim should not respond further. All evidence must be logged and copies saved to disk. The victim can contact the site administrator of the stalker's internet service provider and, if the harassment persists, the police should be notified. Victims are advised to speak with an officer skilled in investigating computer crimes, and ensure that they provide concrete evidence of the cyberstalking (Deirmenjian, 1999).

\section{Other security measures}

There is a range of simple and inexpensive security measures available to victims (see Mullen et al, 2000, p. 237), but the therapist also has an important role in discouraging needlessly expensive or dangerous practices (e.g. buying firearms or turning the home into an inescapable fortress). Self-defence training in disabling techniques that do not require physical strength or years of practice can have an empowering effect.

\section{Clinical management}

The treatment of stalking victims aims to alleviate their distress and restore their interpersonal and
Box 3 Clinical management of stalking victims

Safe and confidential therapeutic setting Education and supportive counselling Cognitive-behavioural therapies for anxiety and avoidance

Pharmacotherapy for psychiatric and physical morbidity

Substance misuse counselling

Family and partner counselling

Support groups

Support organisations

occupational functioning (see Box 3). This requires an eclectic approach that will in some cases extend well beyond the life of the stalking.

Many victims presenting to therapists will have previously sought the help of others, often with little if any success. Some have confronted reactions of disbelief, blame and trivialisation, reinforcing the victim's distrust and disillusionment, self-blame, anger, powerlessness and withdrawal. In order to avoid re-traumatising these individuals, therapists must at the outset adopt an empathic and non-judgemental attitude. They need to provide hope and to establish a trusting alliance by communicating an understanding of stalking and its impact. Above all, it is essential that they convey to the victim that they are not alone and they are not to blame.

It is essential also to provide these individuals with a safe therapeutic environment in which the victim can be assured of the confidentiality of the information imparted. Secretarial and clinical staff must be apprised of security issues and these will need to be reinforced periodically, especially with the appointment of new staff.

\section{Education and supportive counselling}

The provision of information on stalking, especially as this pertains to the victim's particular stalker, can emphasise the commonality of the victim's experience and diminish feelings of helplessness. Some victims think they may be losing their mind and it is necessary to assure them that their symptoms are a normative response to a serious crime. Educating victims helps them to make sense of their situation. It will also place them in a better position to protect themselves and discourage the stalker's advances. Many victims who feel abandoned 
by family and friends simply appreciate the opportunity for a supportive relationship with a trusted confidante.

\section{Cognitive-behavioural approaches}

From the outset, the therapist must allay unreasonable fears and acknowledge realistic ones. Cognitive-behavioural therapy is helpful in restructuring the victim's morbid perceptions of the world, in particular that the world is a malevolent place where nobody can be trusted. It is useful to explore issues such as the victim's sense of personal responsibility and feelings of powerlessness. Anxiety management techniques including deep muscle relaxation and breathing retraining can diminish disabling anxiety symptoms and pave the way for exposure techniques. The latter aim to overcome avoidance behaviours that threaten to isolate the victim and impair their social and occupational functioning. Of course, avoidance behaviours that have a legitimate survival value should not be discouraged.

\section{Pharmacotherapies}

These are an important adjunct to psychological therapies. Stalking victims may present with a range of stress-related symptoms and there is no 'gold standard' pharmacotherapeutic approach. It is important to explain the role of medication to victims and their loved ones, that even though their suffering has been caused by another person some biological changes have occurred that can be normalised by medication (Davidson \& Connor, 1999).

Medications most commonly used are those with efficacy in the treatment of anxiety, depression and PTSD. We find the selective serotonin reuptake inhibitors (SSRIs) most useful with this patient group as they are effective in depression and anxiety disorders and they are generally well tolerated by this largely psychotropic-naïve population. SSRIs are also less toxic in overdose, an important consideration in a group with significant levels of suicidality. They have a broad spectrum of effect on all PTSD symptom clusters, especially hyperarousal (Friedman, 1998), and sertraline has now been approved in the US as a specific treatment for PTSD. In our experience, no particular SSRI is superior to any other in this population.

We would not advocate the prescription of benzodiazepine anxiolytics for victims of stalking, on the basis that dependence may develop where treatment is required for protracted periods. These cases cannot always be predicted at the outset. Furthermore, the disinhibiting potential of the benzodiazepines is cause for concern in a group that, in addition to having high levels of suicidal ideation, may harbour aggressive, if not homicidal, thoughts towards their stalker.

\section{Substance misuse}

As noted earlier, it is not uncommon for victims of stalking to increase their consumption of alcohol, cigarettes and other drugs. Adequate treatment of psychiatric symptoms will minimise the risk of substance misuse and dependence. Non-pharmacological approaches to insomnia should be provided, including advice on avoiding stimulants. Some victims may require referral to specialist drug and alcohol services.

\section{Group therapies}

Therapeutic support groups can play an invaluable role in the rehabilitation of stalking victims. These forums help diminish victims' sense of isolation and alienation, and provide them with an opportunity to vent their anger, loss and frustration in a safe and supportive environment. Such groups can also be a useful resource, with victims exchanging various strategies, reading material and security tips, as well as details of helpful agencies or individuals. Ideally, group facilitators should be mental health professionals well-versed in the practical and emotional issues confronting victims of stalking and in the complex psychological sequelae of this crime.

\section{Family and partner therapies}

It may be necessary to involve the victim's partner and key family members in treatment. This acknowledges the interpersonal disruption and estrangement consequent upon the stalker's intrusions, the helplessness and frustration significant others frequently experience and the unfortunate fact that families and partners are frequently targeted by stalkers. The primary victim's loved ones benefit from education, particularly in relation to the nature of stalking and its impact. This helps maintain the victim's key support networks and ensures the application of more effective and coordinated safety strategies. Some family members who are themselves harassed may require referral for individual counselling. 


\section{Support organisations}

There are a few support organisations specifically for victims of stalking, mostly in the US and UK. They are generally community-funded non-profit organisations that provide a telephone helpline, support and educational material. CyberAngels provides online assistance to victims of cyberstalking. This is a network of thousands of volunteers in over 30 countries that monitors the internet, investigating harassment complaints and providing education and moral support to victims.

\section{False victims}

It is important to identify at the earliest opportunity and treat where possible the condition underlying false claims of victimisation. This will minimise the consumption of precious resources available to genuine victims and the distress such beliefs can generate for the complainant and those they falsely accuse. Delusional victims respond best to antipsychotic medication, although their limited insight makes them notoriously difficult to treat. Those who develop sufficient trust in their therapist may agree to medication on the basis that severe trauma, however subjective, creates high levels of fear and hypervigilance that affect the sufferer's perspective, and that reducing their anxiety will ease their discomfort and clarify the actual extent of the 'harassment'. Low doses of an antipsychotic (e.g. risperidone or olanzapine) are generally well tolerated in this predominantly older population, but the challenge lies in maintaining their compliance, especially when the 'stalking' and associated distress inevitably subsides.

A similar approach is taken with the previously stalked, although most do not require antipsychotics and will respond to cognitive-behavioural measures aimed at better managing their anxiety and re-establishing social networks. Anxiolytic medication, usually one of the SSRIs, is also appropriate in some instances.

Treatment of factitious victims is directed at the underlying personality disorder and accumulated life problems. As for all false victims, it is important to exclude them from victim support groups that will only validate and reify their victim status and expand their knowledge base.

\section{Conclusions}

While stopping the stalker may be the best treatment available to victims, effective management of victims at their earliest presentation reduces long-term morbidity and increases the chances that the stalker will desist. Treatment of stalking victims requires an individually tailored approach that considers the specific nature and context of the harassment as well as the effects upon the victim's significant others. The primary objective is the alleviation of the victim's distress and his or her return to premorbid levels of interpersonal, social and vocational functioning, through the appropriate mix of practical assistance, supportive psychotherapy, cognitive-behavioural treatment and pharmacotherapy. For victims who continue to be harassed, these approaches must always be accompanied by strategies that discourage the stalker's advances and which endeavour to protect the victim and vulnerable third parties.

\section{Useful contacts for victims of stalking}

Information - http: / / www.antistalking.com.au

CyberAngels - http:/ / www.cyberangels.org

Stalking victim support-Survivors of Stalking (SOS) http:/ / www.soshelp.org; Stalking Victims Sanctuary - http://www.stalkingvictims.com; The Suzy Lamplugh Trust - http://www.suzylamplugh.org.

\section{References}

American Psychiatric Association (1994) Diagnostic and Statistical Manual of Mental Disorders (4th edn) (DSM-IV). Washington, DC: APA.

Budd, T. \& Mattinson, J. (2000) The Extent and Nature of Stalking: Findings from the 1998 British Crime Survey. Home Office Research Study 210. London: Home Office Research, Development and Statistics Directorate.

Davidson, J. R. T. \& Connor, K. M. (1999) Management of posttraumatic stress disorder: diagnostic and therapeutic issues. Journal of Clinical Psychiatry, 60, 33-38.

Deirmenjian, J. M. (1999) Stalking in cyberspace. Journal of the American Academy of Psychiatry and Law, 27, 407-413.

Derogatis, L. R. (1977) SCL-90-R: Administration, Scoring, and Procedures Manual 1. Baltimore, MA: Clinical Psychometric Research.

Foa, E. (1995) Posttraumatic Stress Diagnostic Scale. Minneapolis, MN: National Computer Systems, Inc.

Friedman, M. J. (1998) Current and future drug treatment for posttraumatic stress disorder patients. Psychiatric Annals, 28, 461-468.

Goldberg, G. P. \& Hillier, V. F. (1979) A scales version of the General health Questionnaire. Psychological Medicine, 9, 139-145.

Hall, D. M. (1998) The victims of stalking. In The Psychology of Stalking: Clinical and Forensic Perspectives (ed. J. Reid Meloy), pp. 113-137. San Diego, CA: Academic Press.

Horowitz, W., Wilner, N. \& Alvarez, W. (1979) Impact of event scale: a measure of subjective distress. Psychosomatic Medicine, 41, 209-218. 
Howard, R., Castle, D., O’Brien, J., et al (1992) Permeable walls, floors, ceilings and doors. Partition delusions in late paraphrenia. International Journal of Geriatric Psychiatry, 7, 719-724.

Janofsky, J. S. (1994) The Munchausen syndrome in civil forensic psychiatry. Bulletin of the American Academy of Psychiatry and the Law, 22, 489-497.

Jason, L. A., Reichler, A., Easton, J., et al (1984) Female harassment after ending a relationship: a preliminary study. Alternative Lifestyles, 6, 259-269.

MacDonald, A. P., Kessel, V. S. \& Fuller, J. B. (1972) Selfdisclosure and two kinds of trust. Psychological Reports, 30, 143-148.

Mohandie, K., Hatcher, C. \& Raymond, D. (1998) False victimization syndromes in stalking. In The Psychology of Stalking: Clinical and Forensic Perspectives (ed J. Reid Meloy), pp. 226-256. San Diego, CA: Academic Press.

Mullen, P. E. \& Pathé, M. (1994) Stalking and the pathologies of love. Australian and New Zealand Journal of Psychiatry, 28, 469-477.

_ - Purcell, R., \& et al (1999) Study of stalkers. American Journal of Psychiatry, 156, 1244-1249.

- — \& - (2000) Stalkers and Their Victims. Cambridge: Cambridge University Press.

- - \& - (2001) The management of stalkers. Advances in Psychiatric Treatment, 7, 335-342.

Pathé, M. \& Mullen, P. E. (1997) The impact of stalkers on their victims. British Journal of Psychiatry, 170, 12-17.

_ _ — \& Purcell, R. (1999) Stalking: false claims of victimisation. British Journal of Psychiatry, 174, 170-172.

— - \& Purcell, R. (2000) Same-gender stalking. Journal of the American Academy of Psychiatry and the Law, 28, 191197.

Tjaden, P. \& Thoennes, N. (1998) Stalking in America: Findings from the National Violence against Women Survey. Washington, DC: National Institute of Justice and Centers for Disease Control and Prevention, US Department of Justice.

Westrup, D., Fremouw, W. J., Thompson, R. N., et al (1999) The psychological impact of stalking on female undergraduates. Journal of Forensic Sciences, 44, 554-557.

\section{Multiple choice questions}

1. The stalking victim's recovery is likely to be complicated by:

a continued stalking

b a good support network

c poor access to practical assistance

d repeated attempts by the victim to reason with the stalker

e early apprehension of the stalker and mandatory assessment.
2. Restraining orders are likely to be least effective for: a ex-intimates with a deep emotional investment in the victim

b psychotic stalkers

c stalkers who simply want a date with the victim

d stalkers who have breached previous restraining orders without incurring any legal sanctions

e cases where the victim continues to respond to the stalker's advances.

3. It is important to recognise false victims of stalking because:

a police should arrest them

b they consume precious resources available to genuine victims

c they should be banned from psychiatric treatment facilities

d many suffer and require psychiatric treatment

e some pose a danger to themselves and others.

4. Victims stalked by a former intimate are:

a stalked over a shorter period

b at greater risk of threats and physical violence

c likely to experience guilt and self-blame

d are unlikely to suffer psychological symptoms

e often regarded with scepticsim and criticism.

5. Stalking victims should:

a understand they are not to blame

b arrange a conciliation meeting with the stalker

c contact the police only after a restraining order has been breached

d return all unsolicited mail to the stalker

e not suffer in silence.

\section{MCQ answers}

\begin{tabular}{|c|c|c|c|c|}
\hline 1 & 2 & 3 & 4 & 5 \\
\hline a $\quad T$ & a $T$ & a $F$ & a $F$ & a $\mathrm{T}$ \\
\hline b F & b F & b $T$ & b $T$ & b F \\
\hline c $\mathrm{T}$ & c $F$ & c $F$ & c $T$ & c $F$ \\
\hline d $T$ & d $T$ & d $T$ & d F & d F \\
\hline $\mathbf{F}$ & e $T$ & e $T$ & e $T$ & e $T$ \\
\hline
\end{tabular}

